\title{
CARACTERIZAÇÃO DA PISCICULTURA NA REGIÃO DO VALE DO RIBEIRA - SP ${ }^{1}$
}

\author{
Characterization of fish farming in the Ribeira Valley region - SP \\ Daniela Castellani ${ }^{2}$, Walter Barrella ${ }^{3}$
}

\begin{abstract}
RESUMO
Este trabalho buscou caracterizar a piscicultura na Região do Vale do Ribeira quanto aos sistemas de manejo. Estudaram-se quarenta e duas pisciculturas sendo que, destas, 36 praticam o sistema semi-intensivo e seis o sistema intensivo, com os seguintes objetivos: engorda de peixes, produção de alevinos e pesque-pagues. Foram listadas 41 espécies de peixes cultivadas. Apenas 6 espécies são nativas da Bacia do Rio Ribeira de Iguape: lambari (Astyanax sp Linneaus, 1758), traíra (Hoplias malabaricus Bloch, 1794), robalo (Centropomus ssp Cuvier e Valenciennes, 1928), jundiá (Rhamdia quelen Quoy e Gaimard, 1824), cascudo (Hypostomus sp Marschall, 1873) e cará (Geophagus brasiliensis Quoy e Gaimard, 1824). Em 95\% das pisciculturas foram verificadas fugas de peixes exóticos e alóctones dos cultivos. A tilápia nilótica (Oreochromis niloticus Linneaus, 1758) foi a espécie mais freqüente em escapes, e também é a segunda mais cultivada pelos piscicultores, perdendo somente para o pacu (Piaractus mesopotamicus Halmberg, 1887). Foi possível verificar mediante o cálculo da conversão alimentar, que há um desperdício anual de cerca de $32 \%$ da ração utilizada nos cultivos pesquisados. A piscicultura encontra-se em plena expansão nesta região, e já representa a atividade agropecuária mais importante após a bananicultura.
\end{abstract}

Termos para indexação: cultivo de peixes, espécies cultivadas, espécies introduzidas.

\section{ABSTRACT}

The aim of this work was to characterize the fish farming in the Ribeira de Iguape Basin, southern São Paulo State (Brazil), in relation to the management systems. Forty two farms were studied. A semi-intensive system is used by 36 farmers, while an intensive system is used only by 6 studied farmers. Their objectives were raising fish, juvenile fish production and sportive fishery. Forty one fish species were found to be cultivated, but only six were native species from Ribeira Valley: lambari (Astyanax sp Linneaus, 1758), traíra (Hoplias malabaricus Bloch, 1794), robalo (Centropomus ssp Cuvier and Valenciennes, 1928), jundiá (Rhamdia quelen Quoy and Gaimard, 1824), cascudo (Hypostomus sp Marschall, 1873) and cará (Geophagus brasiliensis Quoy and Gaimard, 1824). Fish escapes were observed in 95\% of farms studied, with Nile tilapia (Oreocrhomis niloticus Linneaus, 1758) being the most frequent. The pacu (Piaractus mesopotamicus Halmberg, 1887) and Nile tilapia were the most cultivated species. According to estimation of food conversion, around 32\% of food supplied was wasted yearly. The fish farming is an activity in expansion in the Ribeira Valley and account for the second regional economic activity after banana cultivation.

Index terms: fish farming, cultivated species, introduced species.

(Recebido para publicação em 26 de maio de 2003 e aprovado em $1^{\circ}$ de julho de 2004)

\section{INTRODUÇÃO}

A aqüicultura moderna está embasada em três pilares: a produção lucrativa, a preservação do meio ambiente e o desenvolvimento social. Os três componentes são essenciais e indissociáveis para que se possa ter uma atividade perene. Deve-se entender, portanto, que a preservação ambiental é parte do processo produtivo (VALENTI et al., 2000).

Acredita-se que existam hoje poucos ecossistemas aquáticos naturais que ainda não tenham sido impactados pela atividade humana (WOOTTON, 1992). No Brasil os maiores sistemas naturais estão sendo intensamente modificados pela ação humana. No Estado de São Paulo o elevado grau de degradação ambiental, é responsável pela existência de poucas áreas ainda preservadas. Porém, paradoxalmente, é onde encontramos a maior reserva de Mata Atlântica contínua de território nacional (SANTOS, 1998).
Dentro desse contexto, a Bacia Hidrográfica do Rio Ribeira de Iguape é uma região importante, pois apresenta cobertura vegetal nativa em grande parte do seu território e sua ictiofauna é composta por aproximadamente $95 \%$ de espécies endêmicas (BIZERRIL, 1994).

A piscicultura pode ser uma grande alavanca de desenvolvimento social e econômico, possibilitando o aproveitamento efetivo dos recursos naturais locais e a criação de postos de trabalhos assalariados. Com ela, pode-se produzir alimento de alto valor nutritivo, aproveitando-se diferentes resíduos agropecuários, podendo proporcionar ao piscicultor excelente rentabilidade, gerando riquezas, com ganhos significativos para a economia regional, melhorando assim, a qualidade de vida da população local. Porém, assim como qualquer outra atividade humana, necessita de uma estratégia ou planejamento básico para produzir bons resultados.

1. Parte da dissertação de Mestrado apresentada pelo primeiro autor à UNESP - Rio Claro, SP.

2. Bióloga, Ms. Centro de Estudos Ambientais/UNESP - Rio Claro - daniela.castellani@ig.com.br

3. Biólogo, Dr. Departamento de Ciências do Ambiente/PUC-SP - dinamica@splicenet.com.br 
A criação de peixes se desenvolveu gradativamente, mediante a necessidade básica de alimento. Antigamente, comer peixe era um privilégio das pessoas que viviam perto do mar ou de rios, pois era muito difícil manter os peixes vivos fora do seu ambiente natural. Portanto, populações localizadas longe do mar e rios raramente mantinham peixes em cativeiro. Os primeiros peixes mantidos em cativeiro, provavelmente foram membros da família das carpas (MILLS, 1998).

A piscicultura teve início na China há mais de 2.500 anos, sendo então praticada de maneira rústica, destinando a produção apenas para consumo doméstico. Do Oriente, a piscicultura expandiu-se por toda Europa através da Grécia e Itália. No continente europeu os peixes eram criados inicialmente, em tanques para abastecimento dos refeitórios dos mosteiros. Somente no século passado a piscicultura começou a ser praticada com fins comerciais no Japão, e pesquisas relacionadas com a nutrição de peixes tiveram início nos Estados Unidos da América, na década de 40 (CASTAGNOLLI, 1992).

O Brasil apresenta um dos maiores potenciais para a aqüicultura, pois possui recursos hídricos abundantes e grande extensão territorial. Três quartos de sua área encontram-se na zona tropical, onde recebe energia solar abundante durante o ano todo. Há também um grande número de espécies nativas adequadas para a piscicultura (CASTAGNOLLI, 1992).

A piscicultura é uma atividade antiga na Região do Vale do Ribeira, existindo relatos desta atividade já na década de 30, quando representantes da colônia japonesa iniciaram a criação de carpas em lagos e açudes (BOEGER, 1998). Após esse período inicial, houve um crescimento desta atividade na região, por meio de ações da extinta SUDELPA (Superintendência do Desenvolvimento do Litoral Paulista), que desenvolveu um projeto de fomento da piscicultura na região, em conjunto com a associação de proprietários rurais. Mas foi na década de 90, que a piscicultura viveu um momento de grande expansão, como resultado dos esforços dos produtores locais (BOEGER, 1998). Essa atividade encontra-se ainda em plena expansão no Vale do Rio Ribeira de Iguape e os impactos ambientais da aqüicultura ainda não foram devidamente estudados. Entretanto, já é possível definir os principais aspectos que representam riscos ao ambiente: alterações hidrográficas devido ao intenso represamento e desvio de cursos d'água; e introduções de espécies alóctones e exóticas nos rios da região, já que grande parte das espécies cultivadas atualmente não é nativa da bacia hidrográfica ou mesmo do Brasil (SÃO PAULO, 1997). Um outro risco consiste nas alterações da qualidade da água dos mananciais, já que a maioria das pisciculturas não possui filtros e/ou tratamento dos efluentes dos tanques de cultivo.

Objetivou-se com este trabalho organizar um diagnóstico das características da piscicultura, bem como conhecer a aptidão natural da Região do Vale do Ribeira, além de listar espécies cultivadas e introduzidas na região, buscando desse modo, subsídios para as ações de manejo adequado dos recursos pesqueiros.

\section{MATERIAL E MÉTODOS}

Inicialmente foi obtida uma listagem das pisciculturas cadastradas pelo IBAMA de Iguape e licenciadas pelo DEPRN (Departamento Estadual de Proteção dos Recursos Naturais) de Iguape e Registro, além daquelas cooperadas das duas cooperativas dos aqüicultores de Juquiá e Jacupiranga na região do Vale do Ribeira. As pisciculturas foram visitadas de julho a dezembro de 2001 e durante as visitas técnicas foram aplicados questionários.O questionário de entrevista (Castellani, 2002) foi elaborado visando atender às necessidades do projeto "Os peixes e a pesca na Mata Atlântica do Sul de São Paulo" no âmbito do Programa Biota/Fapesp (proc. no 99/04529-7), e foi composto por 41 questões, enfocando dados sobre o proprietário da piscicultura (nome e endereço); localização da propriedade (coordenadas geográficas); objetivo da piscicultura (engorda, pesque-pague, piscicultura ornamental e alevinagem); sistemas de manejo (semi-intensivo e intensivo) e área das pisciculturas; infra-estrutura do cultivo (instalações de viveiros e tanques-rede); modalidade da piscicultura (monocultivo; policultivo e misto); produtividade; espécies cultivadas; piscicultura ornamental; comercialização de pescado; escapes (avaliação qualitativa realizada por meio de entrevista com pescadores e piscicultores ) e nutrição dos peixes cultivados.

\section{RESULTADOS E DISCUSSÃO}

\section{Localização das pisciculturas}

Foram visitadas 42 pisciculturas, das quais, 24.5\% encontram-se nos municípios de Juquiá, 22.5\% em Registro, 13.5\% em Miracatu, 13.5\% em Iguape, 8.5\% em Sete Barras, 8.5\% em Pariqüera-açu, 6.5\% em Jacupiranga e 2.5\% em Cananéia (Figura 1).

\section{Objetivos das pisciculturas pesquisadas}

Com a exploração da piscicultura na Região do Vale do Ribeira, objetiva-se a engorda de peixes (68\%), ou seja, os piscicultores compram os alevinos com aproximadamente $2 \mathrm{~cm}$ de comprimento, transportam para seus 

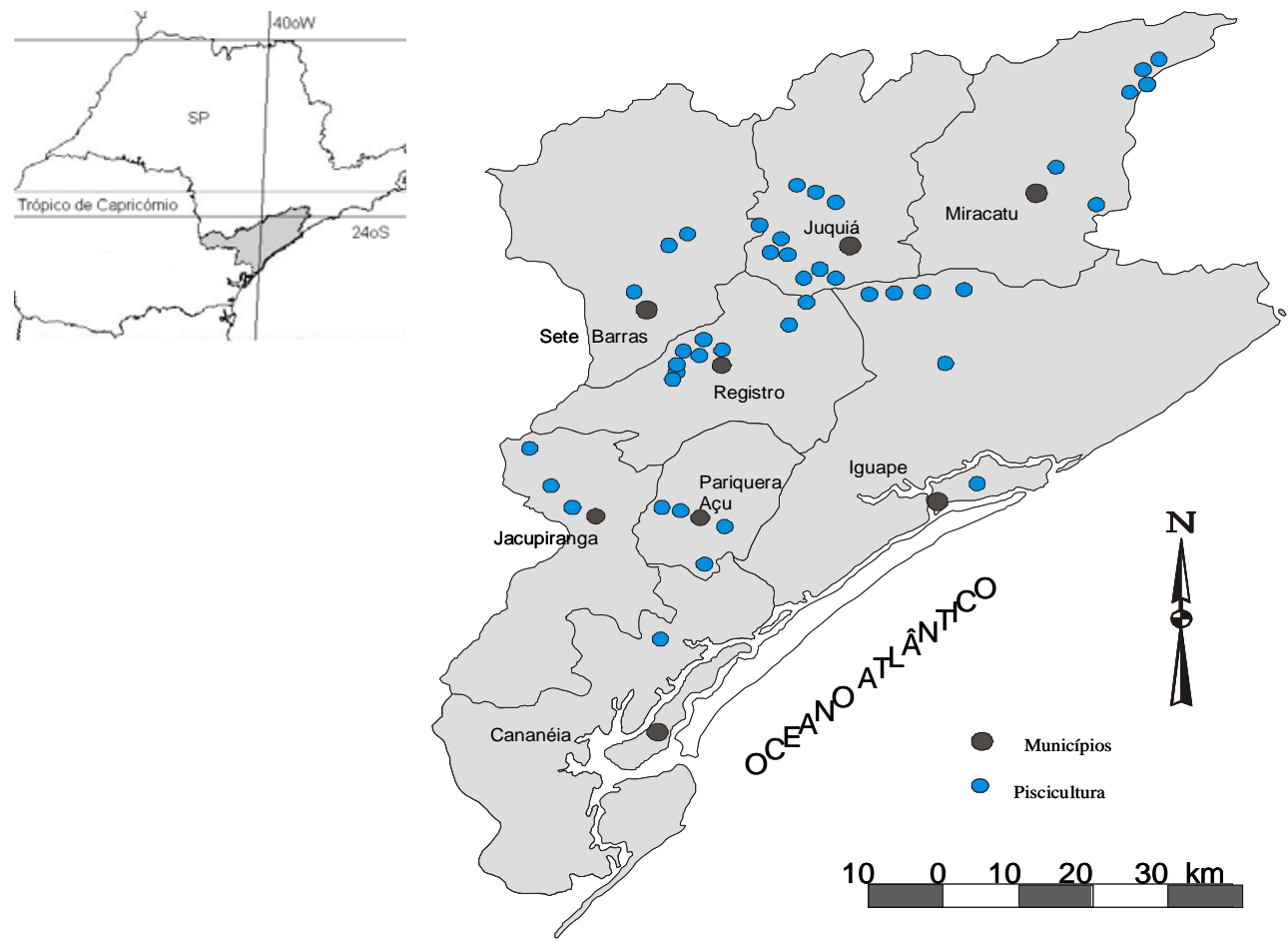

FIGURA 1 - Localização das pisciculturas pesquisadas na Bacia do Rio Ribeira de Iguape, SP.

viveiros e alimentam-os até atingirem seu peso comercial; após isso, geralmente vendem o peixe vivo aos pesquepagues. São freqüentes também os pesque-pagues e pesque-solte (24\%), atividade em moda no momento, a qual atrai pescadores esportivos locais e turistas para a região. Poucos produtores ainda praticam a produção de alevinos (4\%) e cultivo de peixes ornamentais (2\%). Há somente uma empresa que produz em torno de $5 \mathrm{mi}-$ lhões de alevinos por ano e está localizada no município de Cananéia. Isso, também foi constatado por Boeger (1998) e Scorvo (1999). Nesta, a reprodução é feita artificialmente pela hipofisação em casos de peixes reofílicos. Alguns pequenos proprietários utilizam a reprodução natural das tilápias, já que elas se reproduzem bem em cativeiro.

\section{Procedência dos Alevinos}

A procedência dos alevinos das pisciculturas pesquisadas é apresentada na Figura 2. Na Região do Vale do Ribeira, são comprados anualmente mais de 10 milhões de alevinos, pois apenas $8 \%$ dos piscicultores visitados produzem seus próprios alevinos. Muitos produtores adquirem seus alevinos na própria região ou de outros estados, tal como Paraná, Santa Catarina, Mato Grosso do Sul e Goiás. Scorvo (1999) relata que na região de Registro, em 58\% das propriedades os alevinos eram procedentes de outras regiões, o que indica um crescimento de $9 \%$ na origem local destes, quando comparado com o presente estudo.

\section{Sistemas de Manejo e área das pisciculturas}

Foram observados dois tipos diferentes de sistemas de manejo nas 42 pisciculturas pesquisadas: os semi-intensivos em 36 e os intensivos 6 delas. Juntas, estas somam, mais de 103 ha de área em espelho d'água, correspondendo a 37,52 ha (36,6\%) em sistema intensivo (média de 6,2 ha.) e 65,57 ha $(63,4 \%)$ em sistema semi-intensivo (média de 1,6 ha.). Os cultivos intensivos apresentam áreas em espelho d'água maior, devido aos grandes açudes onde estão instalados os tanques-rede com média de 70 peixes por $\mathrm{m}^{3}$ de água. Nos cultivos semi-intensivos os peixes são criados em viveiros, com uma média de 1 peixe por $\mathrm{m}^{2}$ de água. Em todos os cultivos intensivos foi observada a presença de pelo menos 2 aeradores por represas ou açudes. 


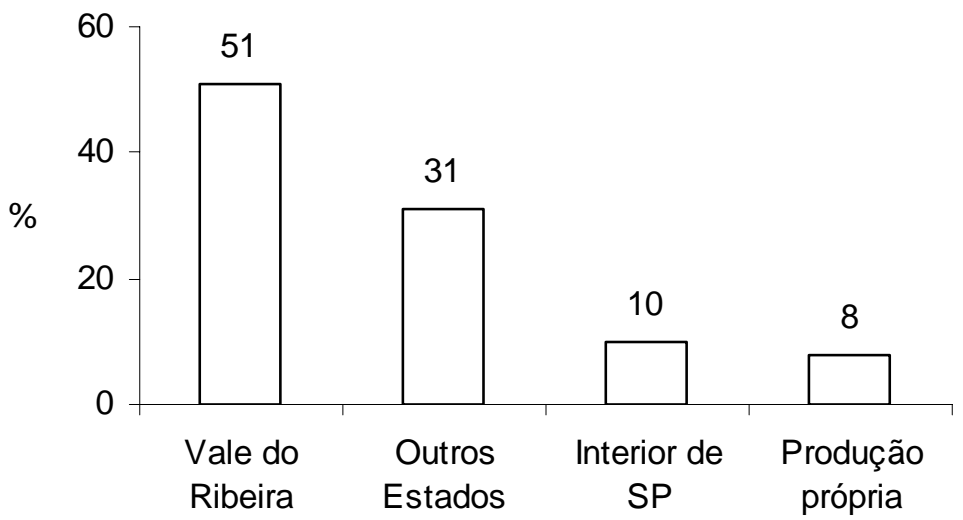

FIGURA 2 - Procedência dos alevinos na região do Vale do Ribeira de Iguape.

\section{Infra-estrutura do cultivo}

As instalações de pisciculturas são extremamente rústicas, predominando em áreas de planície os viveiros convencionais (viveiros escavados) e açudes (viveiros os quais nunca se esvaziam). Os tanques por barramento ocorrem principalmente em terrenos acidentados, aproveitando a declividade da área para a formação de viveiros em diferentes patamares. Também foram observados tanques-rede quadrados ou retangulares de várias dimensões, de tela de metal ou polietileno, com tambores ou bombonas plásticas para sua flutuação. Estas gaiolas estão inseridas em açudes ou grandes viveiros com área superior a meio hectare de água (Tabela 1). Ono e Kubitza (1999) relatam que o tanque-rede obtém altos índices de produtividade devido a constante renovação de água, mantendo assim uma adequada concentração de oxigênio dissolvido e permitindo a eliminação contínua de resíduos orgânicos (fezes e sobras de alimentos) e metabólicos (amônia e gás carbônico).

\section{Modalidade da piscicultura}

Na região, há pisciculturas que praticam três modalidades de cultivo, ou seja, o policultivo (48\%), o monocultivo (38\%) e os dois tipos de cultivo na mesma área, designado como sistema misto (14\%). O monocultivo consiste na criação de uma única espécie num viveiro, tendo sido observado apenas em tilápias ou pacus. As pisciculturas de monocultivo de tilápia também são monosexuais, uma vez que o peixe macho é mais produtivo que a fêmea e pode ser obtido pela adição de hormônios na alimentação (Castagnolli, 1992). O policultivo reúne o cultivo de diferentes espécies de hábitos alimentares distintos em um mesmo viveiro, tendo sido encontradas na região diversas combinações de espécies. Segundo
Wornarovich e Horvath (1985), no bicultivo de carpa e tilápia, ocorre o "sinergismo", com uma espécie influenciando positivamente o crescimento da outra.

\section{Produtividade}

As seis pisciculturas intensivas estudadas produzem anualmente 375 toneladas de peixe (peso vivo) com uma média de 10t ha-1. Dezessete pisciculturas semiintensivas somam um total de 241,8 toneladas anuais, com uma média de 3,5t ha-1. Dezenove pisciculturas semi-intensivas visitadas, ou seja, mais da metade não possuia dados quanto a sua produtividade, pois eram também pesqueiros, e portanto, não controlavam assiduamente a saída de pescado ou por ainda não ter executado a primeira despesca (piscicultura com menos de um ano de atividade).

\section{Espécies cultivadas}

Foram encontradas 41 espécies cultivadas nas pisciculturas pesquisadas, sendo que apenas 6 são nativas, e 28 espécies apresentaram fugas. (Tabela 2 e 3). O pacu (85,5\%), tilápias (do Nilo e San Peter; 82,9\%), tambacu $(75,6 \%)$ e carpas (cabeça-grande, capim e comum; $55 \%$ ) são as espécies mais cultivadas pelos piscicultores. É inte ressante citar que Boeger (1998), afirmou que o pacu e tambacu eram as espécies preferidas pelo piscicultor na região do Vale do Ribeira, representando 60 a $70 \%$ da produção, seguidos pelos bagres e pelo piauçu (cerca de 10 a 15\%) e pelas tilápias (5\% do total produzido). O autor não citou a presença de carpas, na região do Vale do Ribeira, fato a ser contestado, já que esta também é muito cultivada na região. Scorvo (1999) indica o tambacu como a espécie mais cultivada, por apresentar alta produtividade em viveiros e alta disponibilidade de alevinos. 


\section{Piscicultura Ornamental}

Encontramos apenas uma piscicultura (2\% dos entrevistados) com fins ornamentais, que produz plantas aquáticas ornamentais além de peixes de aquários de várias espécies (Tabela 3). O cultivo de peixes ornamentais é considerado hoje um dos setores mais lucrativos da piscicultura brasileira. Ao lado da produção extrativa, abastece um mercado consumidor que, só na América do Norte, abrange mais de cem milhões de aquários residenciais. Esse potencial tem estimulado e impulsionado o setor devido ao crescente aumento da demanda mundial (BERNARDINO e PROENÇA, 2001).

\section{Comercialização de pescado}

A maior parte da produção de peixes produzidos (95\%) abastece os pesque-pagues da própria região do Vale do Ribeira ou da região da Grande São Paulo, e o restante é comercializado no CEASA, nas redes de grandes supermercados, ou ainda, consumido nos restaurantes e hotéis desta região. Isto também foi constatado por Valenti et al. (2000), que declararam que na Região Sudeste os pesqueiros particulares configuram o principal canal de comercialização dos pescados produzidos.

\section{Escapes}

Em 95\% das pisciculturas visitadas foram registradas fugas de pelo menos uma espécie exótica, como resultado da inundação da área onde se criam os peixes, pelo rompimento da parede dos viveiros ou de seus monges, ou ainda pela própria decisão do piscicultor ou pescador desportivo de introduzir espécies novas nos mananciais aquáticos. A tilápia (Oreocrhomis niloticus) foi a espécie que mais apresentou fuga, sendo que os peixes vão principalmente para o canal principal da bacia, onde ocorre a pesca profissional e artesanal. Em entrevista com os pescadores desportivos nos rios Juquiá e Ribeira de Iguape foram observadas e medidas algumas das espécies exóticas introduzidas, tais como a carpa, o pacu, bagre africano, entre outras.

O Brasil está entre os países que têm os maiores números de introdução de peixes exóticos, que atingiram seu pico durante as décadas de 60 e 70, com uma intensa translocação e introdução de espécies da bacia amazônica para o nordeste e sudeste do país (AGOSTINHO et al., 1994). As introduções podem causar modificações nas condições ecológicas locais e alterar a reprodução, o crescimento e o desenvolvimento das espécies nativas, bem como provocar a hibridação, a introdução de doenças e parasitas afetando negativamente a estrutura original do ambiente em questão (WELCOME, 1984; HUNCKINGS et al., 2000). Em $84 \%$ das pisciculturas pesquisadas, confirmou-se a presença de tela nos escoamentos, ou seja, saídas de água dos viveiros, tanques ou açudes. As outras pisciculturas restantes não possuem qualquer barreira que impeça a fuga dos peixes para os mananciais aquáticos, o que pode ser considerado preocupante, já que as espécies introduzidas podem causar impactos ambientais consideráveis.

\section{Nutrição dos peixes cultivados}

O consumo anual de ração está apresentado na Tabela 4. As pisciculturas intensivas representam $41,3 \%$ do consumo de ração (média de $121 \mathrm{t} \mathrm{ha}^{-1} \mathrm{ano}^{-1}$ ) e as semiintensivas, representam 59,7\% (média de $16 \mathrm{t} \mathrm{ha}^{-1} \mathrm{ano}^{-1}$ ). Na maioria das propriedades não é executada a biometria dos peixes para o cálculo da ração mensal, e normalmente a quantidade de ração distribuída nos tanques e viveiros não é adequadamente controlada. Desse modo, o cultivo pode ser prejudicado, pois ração em excesso eleva o nível dos nutrientes das águas dos cultivos, podendo eutrofiza-la; além de proporcionar um aumento no custo de produção. Por outro lado, quando a quantidade de ração é insuficiente leva ao subdesenvolvimento dos peixes nas pisciculturas.

TABELA 1 - Diferentes instalações observadas nas pisciculturas visitadas.

\begin{tabular}{lccc}
\hline \multicolumn{1}{c}{ Tipos de viveiros } & Número & \% & Sistemas de manejo \\
\hline Tanque-rede & 83 & 15,0 & Intensivo \\
Viveiro convencional & 344 & 61,4 & Intensivo e semi-intensivo \\
Barramento & 56 & 10,0 & semi-intensivo \\
Açude & 5 & 0,8 & semi-intensivo \\
Alvenaria & 72 & 12,8 & semi-intensivo (ornamental) \\
Total & 560 & 100 & \\
\hline
\end{tabular}

Ciênc. agrotec., Lavras, v. 29, n. 1, p. 168-176, jan./fev. 2005 
TABELA 2 - Espécies de peixes cultivadas nas pisciculturas comerciais da Região do Vale do Ribeira, número de piscicultores e ocorrências de fugas nos tanques. Piscicultores - número de piscicultores que cultivam a espécie; fugas - número de fugas verificadas nos cultivos durante o período junho a dezembro de 2001.

\begin{tabular}{|c|c|c|c|c|}
\hline $\mathbf{N}^{\mathbf{0}}$ & Nome Comum & Nome Científico & Piscicultores & Fugas \\
\hline 1 & Pacu & Piaractus mesopotamicus (Halmberg,1887) & 35 & 12 \\
\hline 2 & Tilápia-do-nilo & Oreochromis niloticus (Linneaus, 1758) & 34 & 24 \\
\hline 3 & Tambacu & Híbrido (pacu x tambaqui) & 31 & 9 \\
\hline 4 & Sant Peter & Híbrido (vários cruzamentos) & 25 & 16 \\
\hline 5 & Carpa-cabeça-grande & Aristichthys nobilis (Richardson, 1824) & 22 & 9 \\
\hline 6 & Carpa-capim & Ctenopharyngodon idella (Valenciennes, 1844) & 19 & 8 \\
\hline 7 & Tambaqui & Colossoma macropomum (Cuvier, 1818) & 19 & 6 \\
\hline 8 & Traíra & Hoplias molaharicus (Bloch, 1794) & 16 & 2 \\
\hline 9 & Carpa-comum & Cyprinus carpio (Linneaus \& Heckel, 1843) & 15 & 7 \\
\hline 10 & Piau & Leporinus piau (Fowler, 1941) & 12 & 4 \\
\hline 11 & Lambari & Astyanax sp (Linneaus, 1758) & 9 & 1 \\
\hline 12 & Matrinxã & Brycon cephalus (Günther, 1869) & 8 & 1 \\
\hline 13 & Curimbatá & Prochilodus lineatus (Valenciennes, 1836) & 7 & 1 \\
\hline 14 & Paiauçu & Leporinus macrocephalus (Garavello \& Bristski, 1988) & 6 & 1 \\
\hline 15 & Bagre-africano & Clarias gariepinus (Teugels, 1982) & 4 & 2 \\
\hline 16 & Pintado & Pseudoplatystoma corruscans (Spix \& Agassiz, 1829) & 4 & 0 \\
\hline 17 & Trairão & Hoplias lacerdae (Miranda-Ribeiro, 1908) & 4 & 0 \\
\hline 18 & Bagra-de-canal & Ictalurus punctatus (Rafinesque, 1820) & 3 & 1 \\
\hline 19 & Cachara & Pseudoplatystoma fasciatum (Linneaus, 1766) & 3 & 1 \\
\hline 20 & Jundiá & Rhamdia quelen (Quoy \& Gaimard, 1824) & 3 & 0 \\
\hline 21 & Black-bass & Micropterus salmoides (Lacepede, 1802) & 2 & 0 \\
\hline 22 & Dourado & Salminus brasiliensis (Cuvier, 1816) & 2 & 0 \\
\hline 23 & Piapara & Leporinus obtudidens (Valenciennes, 1836) & 2 & 1 \\
\hline 24 & Piraputanga & Brycon hilarii (Valenciennes, 1850) & 2 & 0 \\
\hline 25 & Truta & Onchorhynchus mykiss (Walbaum, 1792) & 2 & 1 \\
\hline 26 & Tucunaré & Cichla ssp (Bloch \& Schneider, 1801) & 2 & 1 \\
\hline 27 & Cará & Geophagus brasiliensis (Quoy \& Gaimard, 1824) & 1 & 0 \\
\hline 28 & Cascudo & Hypostomus sp (Marschall, 1873) & 1 & 0 \\
\hline 29 & Piracanjuba & Brycon orbignyanus (Valenciennes, 1850) & 1 & 0 \\
\hline 30 & Pirapitinga & Piaractus brachypomum (Cuvier, 1818) & 1 & 0 \\
\hline 31 & Robalo & Centropomus ssp (Cuvier \& Valenciennes, 1928) & 1 & 0 \\
\hline 32 & Tuvira & Gymnotus carapo (Cuvier, 1816) & 1 & 0 \\
\hline
\end{tabular}

Ciênc. agrotec., Lavras, v. 29, n. 1, p. 168-176, jan./fev. 2005 
TABELA 3 - Espécies de peixes cultivadas nas pisciculturas ornamentais da Região do Vale do Ribeira, número de piscicultores e ocorrências de fugas nos tanques. Piscicultores - número de piscicultores que cultivam a espécie; fugas - número de fugas verificadas nos cultivos durante o período de existência de cada piscicultura.

\begin{tabular}{cllcc}
\hline $\mathbf{N}^{\mathbf{0}}$ & Nome Comum & \multicolumn{1}{c}{ Nome Científico } & Piscicultores & Fugas \\
\hline 1 & Barbo & Puntius sachsii (Ahl,1923) & 1 & 1 \\
2 & Carpa & Cyprinus carpio (Linneaus \&Heckel, 1843) & 1 & 1 \\
3 & Lebiste & Poecilia reticulata (De Filippi, 1861) & 1 & 1 \\
4 & Molinésia & Poecilia latipina (Lesueur, 1825) & 1 & 1 \\
5 & Paulistinha & Brachydanio rerio (Hamilton, 1822) & 1 & 1 \\
6 & Peixe-anjo & Pterophyllum scalare (Lichtenstein, 1823) & 1 & 1 \\
7 & Peixe-espada & Xiphophorus helleri (Heckel, 1848) & 1 & 1 \\
8 & Peixe-japonês & Carassius auratus (Linneaus, 1758) & 1 & 1 \\
9 & Plati & Xiphophorus maculates (Günther, 1866) & 1 & 1 \\
\hline
\end{tabular}

Nos cultivos visitados são consumidas 1.817 toneladas de rações na produção de $617 \mathrm{t}$ de peixe anualmente, a uma conversão alimentar de 2,9:1 (Tabela 4). Se considerarmos uma conversão alimentar de 2:1, mais adequada para peixes tropicais, é possível perceber que há um excesso anual de cerca de $32 \%$ na ração utilizada nas propriedades pesquisadas e uma perda de lucratividade bruta de cerca de $43 \%$, pois esse excesso de ração tem um custo de $\mathrm{R} \$ 349.800,00$ que poderia ser revertido em lucro, elevando o resultado bruto de $\mathrm{R} \$$ $760.800,00$ para $1.090 .200,00$.

Nas criações semi-intensivas, $30 \%$ das propriedades tratam os peixes a base de frutas (bananas, goiabas e muitas outras) e resíduos de horta, tais como verduras, abóboras, raízes como a mandioca e inhame. Estes produtores, relatam levar vantagem na utilização de subprodutos, pois não consideram que eles representam um custo para a sua produção. Outras 39\% utilizam uma mistura destes produtos e ração e ainda encontramos as que utilizam somente ração $31 \%$. Todas as pisciculturas intensivas também declararam utilizar somente ração para alimentar os peixes do cultivo. Kubitza (1999) afirma que é errôneo o conceito de que um alimento barato sempre reduz o custo de produção e faz aumentar a receita líquida por área de cultivo. Alimentos de alta qualidade apresentam menor potencial poluente e possi- bilitam um aumento na produção por unidade de área, em geral superior ao aumento de custo de produção, resultando em aumento de receita líquida obtida por área de cultivo.

Sugestões para melhoria da atividade de piscicultura no Vale do Ribeira, São Paulo:

Para obtermos o sucesso da atividade da piscicultura e conservação do meio ambiente, seriam recomendáveis as seguintes estratégias: licenciamento das pisciculturas pelo Departamento Estadual de Proteção dos Recursos Naturais (DEPRN) e cadastramento do aqüicultor pelo Ministério da Agricultura; realização de estudos sobre solo, água e topografia para a seleção de local antes da implantação da atividade, por exemplo, para ser evitado a instalação em área de inundação prevenindo o escape de peixe; visitas técnicas de profissionais qualificados para monitoramento da qualidade da água, do cálculo correto de rações, formulações de dietas com maior digestibilidade e menor quantidade de nutrientes e prevenções de enfermidades; o desenvolvimento de projetos que incentivassem a pesquisa sobre produção de espécies nativas como o jundiá e o robalo, e o tratamento dos efluentes das pisciculturas; o desenvolvimento de cursos de capacitação para os responsáveis pelos cultivos, podendo ser planejados em parceria com as duas cooperativas de aqüicultores da região. 
TABELA 4 - Custo do peixe e ração nas pisciculturas pesquisadas (conversão alimentar 2,9:1).

\begin{tabular}{lccc}
\hline & $\begin{array}{c}\text { Quantidade } \\
(\mathbf{t})\end{array}$ & $\begin{array}{c}\text { Custo unitário } \\
\mathbf{( R \mathbf { ~ K g }}\end{array}$ & $\begin{array}{c}\text { Custo Total } \\
\mathbf{( R \mathbf { } )}\end{array}$ \\
\hline Ração consumida anualmente & 1.817 & 0,60 & $1.090 .200,00$ \\
Produção de pescado anual & 617 & 3,00 & $1.851 .000,00$ \\
$\quad$ Lucro bruto anual & & & $760.800,00$ \\
\hline
\end{tabular}

$(U \$ 1,00=R \$ 3,63$ e $€ \$ 1,00=R \$ 3,67$ em novembro de 2002).

\section{CONCLUSÕES}

Na Região do Vale do Ribeira são praticadas pisciculturas nos sistema semi-intensivos e intensivos, muitas destas com mais de dez anos em atividade, cultivando-se 32 espécies de peixes comerciais e mais de 10 espécies ornamentais.

A fuga de peixes exóticos da pisciculturas para os rios e riachos já é um fato comprovado na região.

A maioria das pisciculturas pesquisadas, utilizam quantidade excessiva de ração na alimentação dos peixes.

\section{AGRADECIMENTOS}

Os autores agradecem a Cooperpeixe (Edmir Nardino e Vastir), Codesalq (Msc. Paulo Colherinhas) e proprietários das pisciculturas pesquisadas, pelo apoio na execução deste estudo. Ao estagiário Ricardo Pinze dos Santos pelo apoio no trabalho de campo. Ao Prof. Dr. Marcos Pereira Marinho Aidar pela análise crítica do manuscrito. Este estudo foi financiado pelo projeto BIOTA/FAPESP "Peixes e pesca na Mata Atlântica do sul de São Paulo” (processo: 1999/04529-7).

\section{REFERÊNCIAS BIBLIOGRÁFICAS}

AGOstinho, A. A.; JULiO, H. F.; PETRERE JUNIOR, M. Itaipu Reservoir (Brasil) impacts of the impoundnment on the fish fauna and fisheries. In: Cowx, I. G. (Ed.). Rehabilitation of freshwater fisheries. London: Fishing New Books, 1994. p. 171184.

BERNARDINO, G.; PROENÇA, C. E. M. Agronegócios de peixes ornamentais no Brasil e no mundo. Revista Panorama da Aqüicultura, Rio de Janeiro, v. 11, n. 65, p. 14-24, maio/junho 2001.
BIZERRIL, C. R. S. F. Análise taxonômica e biogeográfica da ictiofauna de água doce do leste brasileiro. Acta Biologica Leopoldensia, São Leopoldo, v. 16, p. 51-80, 1994.

BOEGER, W. A. Cadeia produtiva da aqüicultura do Vale do Ribeira, SP. Curitiba: UFPR, 1998. 23 p. Relatório técnico.

CASTAGNOLLI, N. Criação de peixes de água doce. Jaboticabal: FUNEP, 1992. 189 p.

CASTELLANI, D. Caracterização da piscicultura na região sul de São Paulo (Brasil). 2002. 79 f. Dissertação (Mestrado em Conservação e Manejo de Recursos) - Centro de Estudos Ambientais, Universidade Estadual Paulista, Rio Claro, 2002.

HUNCKINGS, C. J. F.; OSENBERG, C. W.; MITTELBACH, G. Species introductions and their ecological consequences: an example with congeneric sunfish. Ecological Applications, Tempe, v. 10, p. 612-625, 2000.

KUBITZA, F. Qualidade da água na produção de peixes. Piracicaba: ESALQ, 1999. $51 \mathrm{p}$.

MILLS, D. Peixes de aquário. Rio de Janeiro: Ediouro, 1998. $304 \mathrm{p}$.

ONO, E. A.; KUBITZA, F. Cultivo de peixes em tanques redes. 2. ed. Jundiaí: [s.n.], 1999. 68 p.

SANTOS, M. R. A variabilidade ambiental e as comunidades de peixes do Rio Ribeira de Iguape (SP). 1998. 109 f. Dissertação (Mestrado) - Universidade Estadual Paulista, Jaboticabal, 1998.

SÃO PAULO. Secretaria do Meio Ambiente. Diagnóstico ambiental participativo do Vale do Ribeira e litoral sul de São Paulo. São Paulo, 1997. 87 p. 
SCORVO, J. D. F. Avaliação técnica e econômica das piscigranjas de três regiões do estado de São Paulo. 1999. 120 f. Dissertação (Mestrado) - Centro de Aqüicultura, Universidade Estadual Paulista, Jaboticabal, 1999.

VALENTI, W. C.; PEREIRA, J. A.; BORGHETTI, J. R. Aqüicultura no Brasil: bases para um desenvolvimento sustentável. Brasília: CNPq; Ministério da Ciência e Tecnologia, 2000. 399 p.
WELCOME, R. L. International transfers of inland fish specie: distribution, biology and management of exotic fishes. London: The John Hopkins University, 1984. v. 1, 430 p.

WOOTTON, R. J. Fish ecology. New York: Champman and Hall, 1992. v. 1, 212 p.

WORNAROVICH, E.; HORVATH, L. A. Propagação artificial de peixes de águas tropicais: manual de extenção. Brasília, DF: FAO/CODEVASF/CNPq, 1985. 220 p. 